\title{
A Case of Basal Cell Carcinoma of External Auditory Canal
}

\author{
Beom-Jun Lee, Seong-Cheon Bae, Jae-Hong Lee and Kyoung-Ho Park \\ Department of Otolaryngology-Head \& Neck Surgery, The Catholic University of Korea College of Medicine, Seoul, Korea
}

\author{
Received June 4, 2012 \\ Revised July 20, 2012 \\ Accepted August 2, 2012

Address for correspondence
Kyoung-Ho Park, MD, PhD
Department of Otolaryngology-Head
\& Neck Surgery, The Catholic
University of Korea
College of Medicine,
222 Banpo-daero, Seocho-gu,
Seoul 137-701, Korea
Tel +82-2-2258-6213
Fax+82-2-595-1354
E-mail khpent@catholic.ac.kr \\ Address for correspondence \\ Kyoung-Ho Park, MD, PhD \\ $\&$ Neck Surgery, The Catholic \\ University of Korea \\ 222 Banpo-daero, Seocho-gu, \\ Seoul 137-701, Kore \\ Fax +82-2-595-1354 \\ E-mail khpent@catholic.ac.kr
}

\begin{abstract}
Malignant tumor originated from external auditory canal (EAC) is very rare with an annual incidence of around 1 per million. Pathologically, squamous cell carcinoma is incidentally most common, and adenoid cystic carcinoma, basal cell carcinoma, and melanoma follow in decreasing order. Due to the rarity of malignant tumor of EAC, there is no widely accepted treatment modality yet. But basal cell carcinoma, known to be less aggressive tumor, can be removed with a minimal safety margin and have better treatment results. Recently we experienced a case of basal cell carcinoma in the EAC, confined in the cartilaginous portion of EAC, presenting with intermittent otorrhea for several years. The patient was treated with a sleeve resection of the EAC with a safety margin reconstructed with a split-thickness skin graft. No tumor recurrence or complication was noted in the first postoperative year.
\end{abstract}

Korean J Audiol 2012;16:91-94

KEY WORDS: Basal cell carcinoma · External auditory canal · Sleeve resection . Split-thickness skin graft.

\section{Introduction}

Carcinomas of external auditory canal (EAC) are very rare with an annual incidence of around 1 per million people. ${ }^{1 .}$ Even large centers only see few patients. Because of the rarity, consensus regarding the treatment of carcinomas of EAC is inadequate. Although some progress in treating this disease has been made over the decades, guidelines and treatment protocols are still needed. Among these tumors, basal cell carcinomas are less frequently noted than squamous cell carcinomas.

The authors will describe a case of basal cell carcinoma located in the EAC and the treatment experience with a review of the literature.

\section{Case Report}

A 55-year-old female in otherwise good health presented with a 10-year history of an intermittent otorrhea in the right ear.

A physical examination revealed a small nodular mass arising from the posterior inferior aspect of the right cartilaginous portion of the EAC (Fig. 1). Right tympanic membrane was intact.

Other clinical examinations including the head and neck region, laboratory findings, and audiologic findings were with- in normal limits. It appeared to be a benign lesion of EAC, an excisional biopsy was performed under local anesthesia. Contrary to expectation, histologic examination was interpreted as a basal cell carcinoma (Fig. 2). Fortunately, surgical margin was negative for malignancy. Further evaluation of the temporal bone by computed tomography (CT) and a magnetic resonance imaging (Fig. 3) of the head and neck showed no involvement of any other temporal bone or of head and neck structures.

Although less probable, because distant metastasis cannot be ruled out completely, a full metastatic workup was done. Bone scan, hepatobilliary sonography, duodenoscopy, chest X-ray, and CT of the chest, PET-CT were all negative for signs of nodal involvement or metastases to other organs.

According to the Pittsburgh staging system, ${ }^{2)}$ the patient had tumor limited to the EAC without bony erosion or evidence of soft tissue involvement (T1), no lymph node metastases (N0), and no distant metastases (M0).

The patient underwent sleeve resection of the EAC reconstructed with a coverage of the EAC using a left thigh splitthickness skin graft (Fig. 4). Pathologic findings confirmed a basal cell carcinoma in situ not invading cartilage, all surgical margins being free of invasion (Fig. 2). No adjuvant chemotherapy or radiation was administered. 
After 1 year of surgery, the patient is in good health with no evidence of complication or recurrence (Fig. 5).

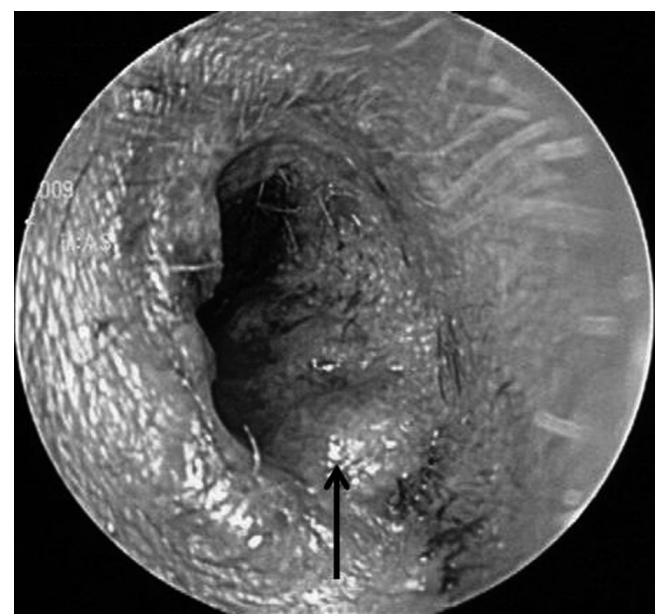

Fig. 1. Photograph of right external auditory canal taken preoperatively. There is a small nodular mass (arrow, $1.5 \times 1.2 \mathrm{~cm}$ ) arising from the posterior inferior aspect of the right cartilaginous portion of the external auditory canal.

\section{Discussion}

Among carcinomas of EAC, squamous cell carcinoma (SCC) is the most common, accounting for $80 \%$ of tumors within the temporal bone. ${ }^{3)}$ Basal cell carcinoma, adenoid cystic carcinoma, adenocarcinoma, melanoma, and various sarcoma are among the other malignancies within the temporal bone. ${ }^{4)}$

In 1990, the Pittsburgh group proposed a staging system for SCCs of the EAC. Arriaga, et al. ${ }^{2)}$ proposed a primary tumor, regional nodes, metastasis (TNM) staging of EAC carcinoma on the basis of clinical examination, and preoperative CT scan finding. ${ }^{2,5)}$ Other authors have supported the clinical usefulness of this staging. ${ }^{6,7)}$ The classification method proposed by Arriaga, et al. ${ }^{2}$ is advantageous with regard to treatment, because it correlates the clinical and radiologic characteristics in patients.

Because of the rarity of malignant tumor of EAC, there are no randomized clinical trials. Therefore, the management of these tumors is difficult. In the several studies, authors disagree
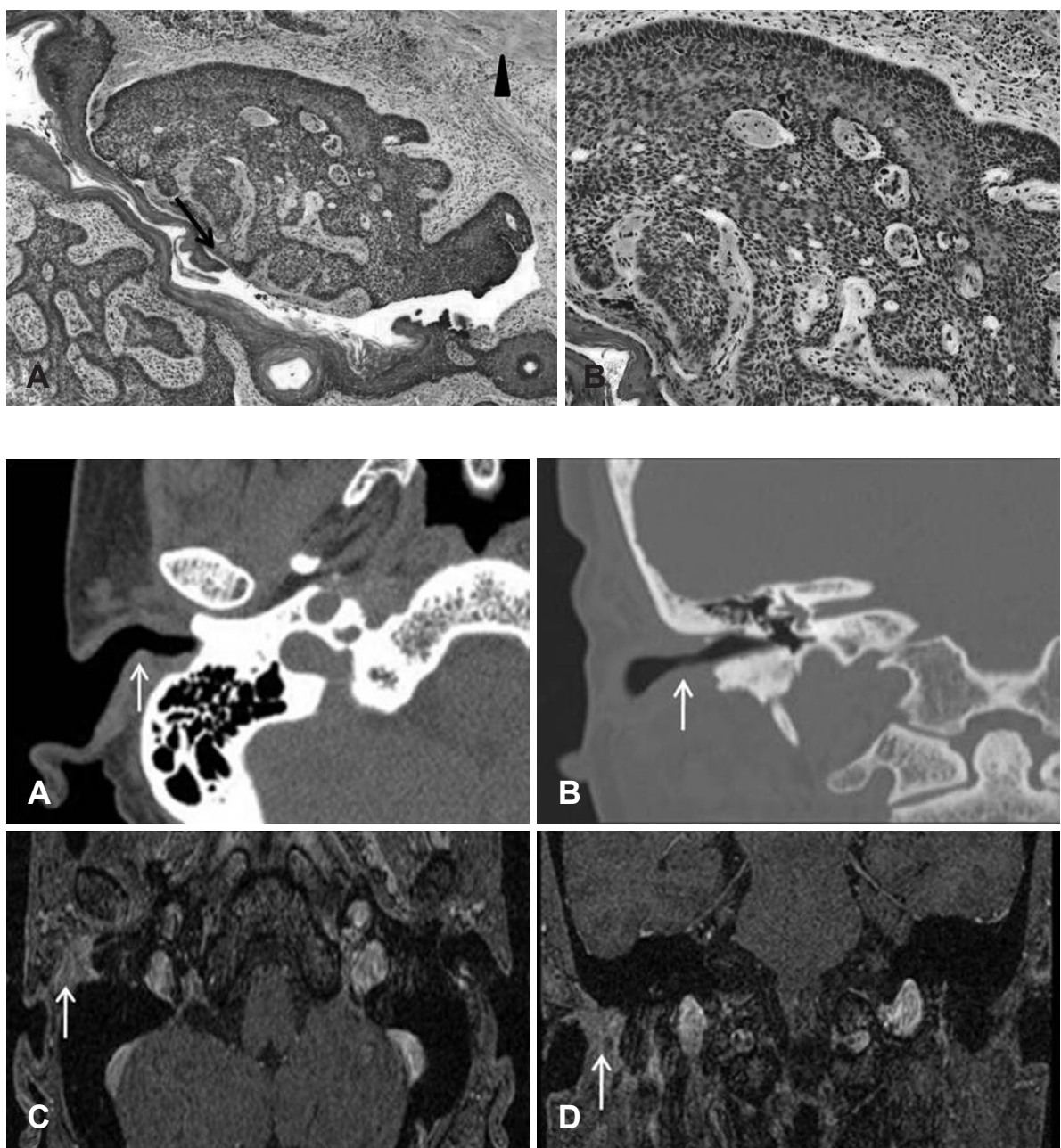
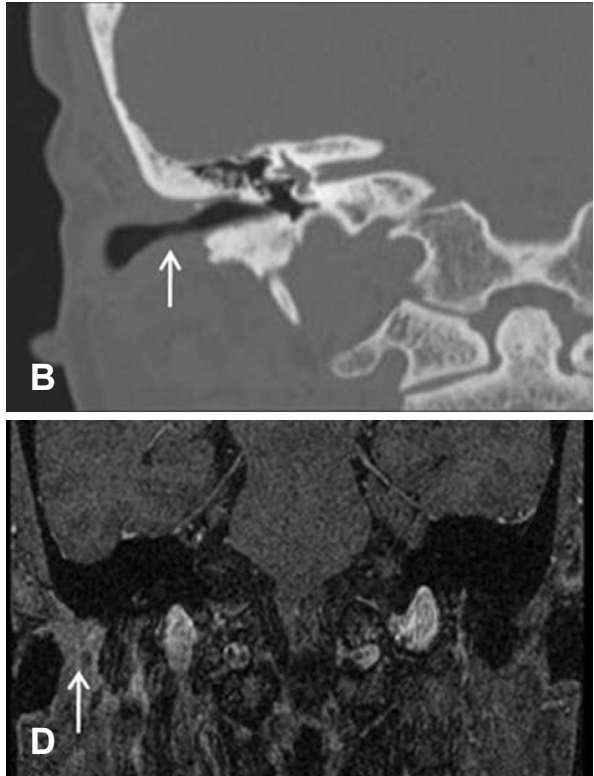

Fig. 2. The histopathologic photography of the tumor. A: The tumor cells typically form lobule extending from the basal layer (arrow) of epidermis into more superficial or deep layers without invading cartilage (arrow head)(hematoxylin-eosin original magnification, $\times 100)$. B: The cells show little pleomorphism and have large oval hyperchromatic nuclei with minimal cytoplasm (hematoxylineosin original magnification, $\times 200$ ).
Fig. 3. Temporal bone computed tomography. This shows narrowing of the extenal auditory canal and a small nodule (arrow, $5 \mathrm{~mm}$ in diameter) at the posterior wall of the right external auditory canal. A: Axial view. B: Coronal view. T1-weighted magnetic resonance imaging enhanced by Gadolinium. There is about 1.3 $\mathrm{cm}$ sized contrast enhancing mass lesion (arrow) at the lateral aspect of right external auditory canal and no definite abnormality in both middle and inner structures. C: Axial view. D: Coronal view. 

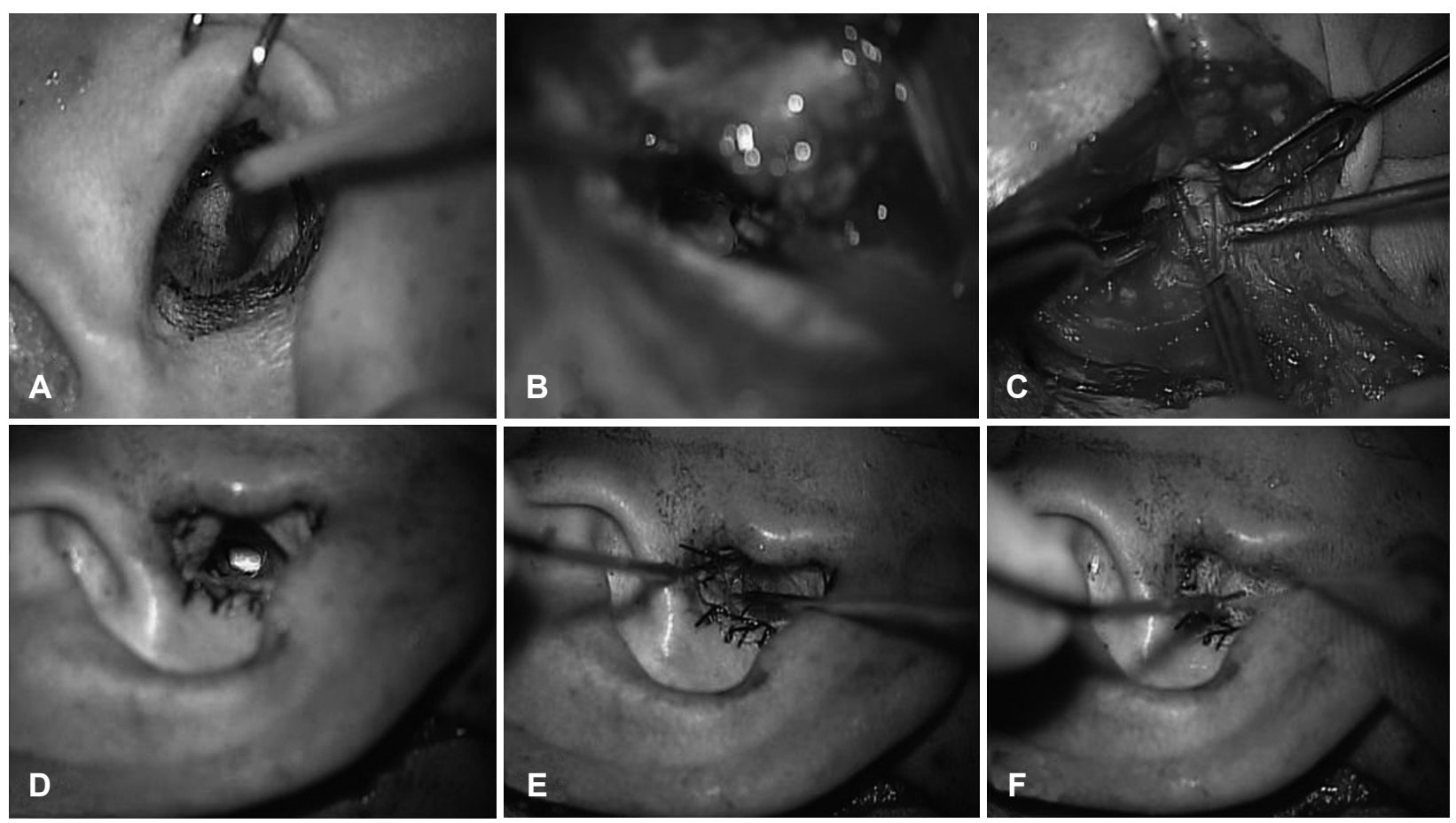

Fig. 4. Procedure of sleeve resection. A: Transcanal incision was done surrounding mass lesion in the right external auditory canal. B: Postauricular incision was done posterior $0.5 \mathrm{~cm}$ site from post auricular fold. EAC skin elevated to $5 \mathrm{~mm}$ site lateral from annulus. C: Wide excision was made including cartilaginous portion of the EAC with $0.2 \mathrm{~cm}$ excision margin. Frozen biopsy of all excision margin was negative. D: The defect was reconstructed with prepared thigh split thickness skin graft. Lateral margin of thigh skin sutured with orifice of the ear. E, F: Packing was done tightly with gelform and furacin gauze in the external auditory canal. EAC: external auditory canal.

Fig. 5. Photograph of external auditory canal taken 1 year postoperatively, showing skin graft on a reconstructed external auditory canal.

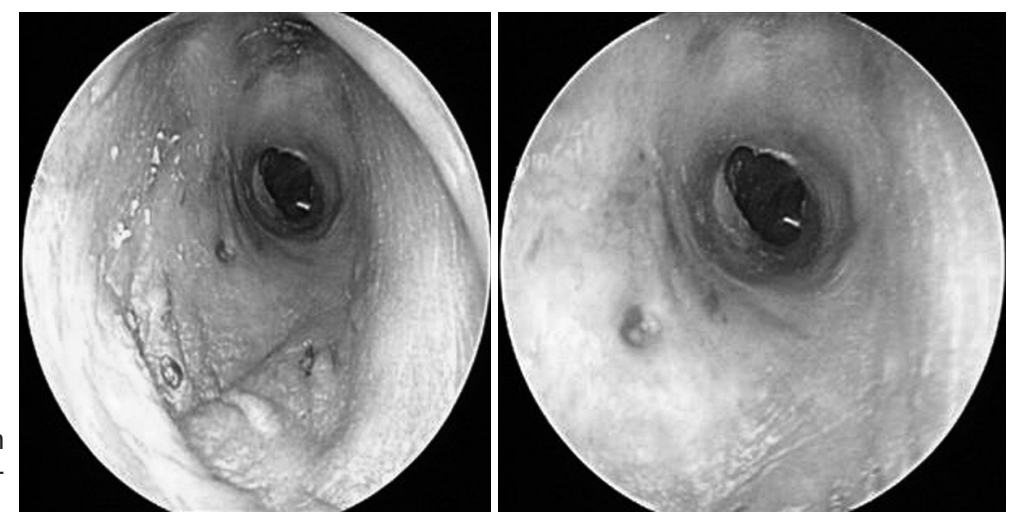

about the extent of surgery and the role of radiotherapy and chemotherapy in managing these tumors. Gidley ${ }^{8)}$ reviewed several literatures and discussed about treatment strategies focused on the carcinoma of EAC. Early stage tumors can be managed with a surgery alone reserving radiation as a component of salvage options. Small T1 tumors that are confined to the soft tissues, cartilaginous ear canal can be removed with wide local excision, where the skin of the ear canal and the underlying cartilage are removed with frozen section medial margins. This operation must be selected for limited tumors that do not cross medially over the bony-cartilaginous junction. $\mathrm{T} 1$ tumors of the bony ear canal and $\mathrm{T} 2$ tumors (i.e., those with limited bony or soft tissue involvement) are best controlled with lateral temporal bone resection.

Basal cell carcinoma of the EAC is known to have a locally aggressive nature and lack of regional lymph node metastasis. Basal cell carcinomas are less lethal because of their slower growth rate and rare metastasis. ${ }^{9,10)}$ Because there is a possibility of distant metastasis, evaluation must be completed before treatment plan is established. In 2002, Nyrop and Grøntved $^{11)}$ evaluate the result of surgically treated cancer of EAC in twenty consecutive patients. The authors concluded that the outcome was related to the stage of disease, suggesting that the Pittsburgh staging system is also useful in patients 
with non-SCC.

Patients with early cancer benefited from less aggressive surgical approach, while survival was poor in patients with an advanced cancer who went through a more aggressive surgery despite adjuvant radiotherapy. ${ }^{9,12)}$

Fortunately, our patient had tumor limited to the EAC without bony erosion or evidence of soft tissue involvement (T1), no lymph node metastases (N0), and no distant metastases (M0).

Using the treatment strategies described above on the carcinoma of the EAC, we can remove the tumor with a minimal safety margin and have better treatment results.

\section{REFERENCES}

1) Kuhel WI, Hume CR, Selesnick SH. Cancer of the external auditory canal and temporal bone. Otolaryngol Clin North Am 1996;29: 827-52.

2) Arriaga M, Curtin H, Takahashi H, Hirsch BE, Kamerer DB. Staging proposal for external auditory meatus carcinoma based on preoperative clinical examination and computed tomography findings. Ann Otol Rhinol Laryngol 1990;99(9 Pt 1):714-21.

3) Moffat DA, Wagstaff SA. Squamous cell carcinoma of the temporal bone. Curr Opin Otolaryngol Head Neck Surg 2003;11:107-11.

4) Devaney KO, Boschman CR, Willard SC, Ferlito A, Rinaldo A. Tumours of the external ear and temporal bone. Lancet Oncol 2005;6: 411-20.

5) Arriaga M, Curtin HD, Takahashi H, Kamerer DB. The role of preoperative CT scans in staging external auditory meatus carcinoma: radiologic-pathologic correlation study. Otolaryngol Head Neck Surg 1991;105:6-11.

6) Austin JR, Stewart KL, Fawzi N. Squamous cell carcinoma of the external auditory canal. Therapeutic prognosis based on a proposed staging system. Arch Otolaryngol Head Neck Surg 1994;120:122832.

7) Moody SA, Hirsch BE, Myers EN. Squamous cell carcinoma of the external auditory canal: an evaluation of a staging system. Am J Otol 2000;21:582-8.

8) Gidley PW. Managing malignancies of the external auditory canal. Expert Rev Anticancer Ther 2009;9:1277-82

9) Testa JR, Fukuda Y, Kowalski LP. Prognostic factors in carcinoma of the external auditory canal. Arch Otolaryngol Head Neck Surg 1997:123:720-4.

10) Brunner H. Basal-cell carcinoma of the external auditory canal and middle ear. AMA Arch Otolaryngol 1953;58:665-76.

11) Nyrop M, Grøntved A. Cancer of the external auditory canal. Arch Otolaryngol Head Neck Surg 2002;128:834-7.

12) Prasad S, Janecka IP. Efficacy of surgical treatments for squamous cell carcinoma of the temporal bone: a literature review. Otolaryngol Head Neck Surg 1994;110:270-80. 